\title{
Prussian Blue onto Activated Carbon as a Catalyst for Heterogeneous Fenton-Like Processes
}

\author{
Lucila I. Doumic, Gabriel Salierno, Miryan C. Cassanello, Patricia M. Haure, and María A. Ayude
}

\begin{abstract}
The main goal of this contribution is the development of a new heterogeneous Fenton-like oxidation system based on Prussian Blue supported over a commercially available granular activated carbon (GAC). The catalysts were prepared following basically three different approaches: (i) Prussian Blue $\left(\mathrm{Fe}_{3}\left[\mathrm{Fe}(\mathrm{CN})_{6}\right]_{2}\right)$ particles adsorbed onto the GAC by impregnation, (ii) Prussian Blue nanoparticles (PBNP) prepared ex-situ and adsorbed onto the GAC; and (iii) PBNP prepared in-situ onto the GAC. The catalysts were characterized by SEM, EDS, BET surface area and Fe content. Their performance in the catalytic wet peroxide oxidation of a model azo dye, Orange G, was tested in a batch lab-scale stirred reactor. Activity and stability runs were carried out and analyzed in terms of dye discoloration, Total Organic Carbon removal, UV-vis spectra and degree of iron leaching.
\end{abstract}

Index Terms-Activated carbon, azo dye, heterogeneous fenton-like oxidation, prussian blue nanoparticles.

\section{INTRODUCTION}

The development of Advanced Oxidation Processes (AOPs) to achieve complete mineralization of recalcitrant compounds is a topic of great interest [1]. Among the AOPs, Fenton reaction is very appealing because of its simplicity and the low price, availability and small toxicity of its reagents. However, it presents disadvantages such as limited $\mathrm{pH}$ range, production of $\mathrm{Fe}$ containing sludge, and deactivation. Thus, heterogeneous Fenton or Fenton-like degradation processes appear as a practical way to overcome these limitations. Activated carbons (ACs) have emerged as a good choice for oxidation processes working as catalysts themselves [2], [3] or as catalyst supports [4], [5]. Adsorption and reaction co-exist in heterogeneous AC supports, largely determining the performance of the oxidation process.

The mixed-valence Prussian Blue $\left(\mathrm{Fe}_{3}\left[\mathrm{Fe}(\mathrm{CN})_{6}\right]_{2}\right)(\mathrm{PB})$ is an inorganic polycrystal with well-known electrochromic and electrocatalytical properties [6]. Recently, [7] showed that the mixture of Prussian blue (iron hexacyanoferrate) colloids and hydrogen peroxide can function as a heterogeneous Fenton reagent. Reference [8] reported excellent catalytic activity towards the oxidation of Methylene Blue.

The main goal of this work is the development of a new

Manuscript received May 31, 2013; revised July 29, 2013. This work was supported by CONICET, UBA, UNMdP and ANPCyT.

L. I. Doumic, P. M. Haure, and M. A. Ayude are with the División de Catalizadores y Superficies. Intema. Facultad de Ingeniería J.B. Justo 4302. 7600 Mar del Plata, Argentina (e-mail: luciladoumic @ fi.mdp.edu.ar).

G. Salierno and M. C. Cassanello are with the Pinmate, Dep. Industrias, FCEyN, UBA, Intendente Güiraldes 2620, C1428BGA, Buenos Aires, Argentina (e-mail: author@lamar. colostate.edu). heterogeneous Fenton-type oxidation system. With the aim of mitigating iron leaching, catalysts containing PB particles adsorbed onto granular activated carbons (GAC) were prepared, characterized and tested in the heterogeneous oxidation of the azo dye Orange $G$ in the presence of hydrogen peroxide.

\section{EXPERIMENTAL METHODS}

\section{A. Catalysts Preparation and Characterization}

A commercially available granular (particle diameter $=2$ $\mathrm{mm}$ ) activated carbon was selected as support in all cases.

The first three catalysts were prepared impregnating the GAC by sequential addition of aqueous solutions of $\mathrm{K}_{3}$ $\left[\mathrm{Fe}(\mathrm{CN})_{6}\right]$ and $\mathrm{FeSO}_{4}$ to produce Prussian Blue $\left(\mathrm{Fe}_{3}\left[\mathrm{Fe}(\mathrm{CN})_{6}\right]_{2}\right)$ particles in situ, which remain adsorbed onto the support with different iron contents; the influence of the addition order and the repeated impregnation was examined. Alternatively, Prussian Blue nanoparticles (PBNP) were prepared ex-situ and adsorbed onto the GAC. A typical synthetic procedure was used to get the PBNP, based on the reaction between $\mathrm{FeCl}_{3}$ and $\mathrm{K}_{3} \mathrm{Fe}(\mathrm{CN})_{6}$ using $\mathrm{H}_{2} \mathrm{O}_{2}$ as a reducing agent. The effect of adding the reducer gradually (as suggested by [9]) or suddenly, was studied. Finally, the PBNP precipitation was induced in situ, that is, using the GAC itself as a reducer. The impact of a simultaneous or separate addition of the solutions of $\mathrm{FeCl}_{3}$ and $\mathrm{K}_{3} \mathrm{Fe}(\mathrm{CN})_{6}$ was investigated. All chemicals used for catalysts preparation and oxidation tests were analytical grade without any further purification. The total Fe content in the prepared catalysts was determined spectrophotometrically after solid degradation. Table I details the preparation procedures and the total Fe content of each prepared catalyst.

The morphology of the fresh catalysts was examined by scanning electron microscopy (SEM) and the superficial iron distribution was mapped with Energy Dispersive X-ray Spectroscopy (EDS).

Specific areas of the GAC and the prepared catalysts (fresh and used) were determined from $\mathrm{N}_{2}$ adsorption isotherms at $77 \mathrm{~K}$

\section{B. Adsorption and Oxidation Experiments}

Tests were conducted in a thermostated stirred glass batch reactor with $200 \mathrm{~cm}^{3}$ capacity. Catalyst was placed into a basket to mitigate particles abrasion arising from the stirring. To start each test, $175 \mathrm{~cm}^{3}$ of an Orange G (OG) aqueous solution was placed into the reactor. The $\mathrm{pH}$ was initially adjusted to the desired value by using $1.0 \mathrm{~mol} / \mathrm{dm}^{3} \mathrm{H}_{2} \mathrm{SO}_{4}$ or $1.0 \mathrm{~mol} / \mathrm{dm}^{3} \mathrm{NaOH}$ and it was measured with a $\mathrm{pH}$-mete from HANNA instruments. Reaction was initiated by adding 
calculated amounts of $\mathrm{H}_{2} \mathrm{O}_{2}$ and the basket containing the corresponding catalyst into the reactor. The initial operating conditions were: $\mathrm{pH}=3, \mathrm{~T}=323 \mathrm{~K}, \quad$ [catalyst] $=2.6 \mathrm{~kg} / \mathrm{m}^{3}$, $[\mathrm{OG}]=0.2 \mathrm{~mol} / \mathrm{m}^{3}$ and $\left[\mathrm{H}_{2} \mathrm{O}_{2}\right]=18 \mathrm{~mol} / \mathrm{m}^{3}$. The uncontrolled $\mathrm{pH}$ remains almost constant along the reaction in all experiments. The catalytic activity was evaluated by measuring discoloration, Total Organic Carbon (TOC) and UV-visible spectra along the reaction time. Liquid samples were taken out periodically and analyzed at once.

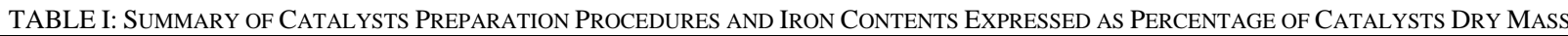

\begin{tabular}{|c|c|c|}
\hline Tag & Preparation procedure & $\% \mathrm{Fe}$ \\
\hline GAC-PB1 & Sequential impregnation: $\mathrm{FeSO}_{4} 0.012 \mathrm{~mol} / \mathrm{dm}^{3} 30 \mathrm{~min}+\mathrm{K}_{3}\left[\mathrm{Fe}(\mathrm{CN})_{6}\right] 0.2 \mathrm{~mol} / \mathrm{dm}^{3} 30 \mathrm{~min}$ & 0.2 \\
\hline GAC-PB2 & Sequential impregnation $\mathrm{K}_{3}\left[\mathrm{Fe}(\mathrm{CN})_{6}\right] 0.2 \mathrm{~mol} / \mathrm{dm}^{3} 30 \mathrm{~min}+\mathrm{FeSO}_{4} 0.012 \mathrm{~mol} / \mathrm{dm}^{3} 30 \mathrm{~min}$ & 0.2 \\
\hline GAC-PB3 & Repeated sequential impregnation $\mathrm{K}_{3}\left[\mathrm{Fe}(\mathrm{CN})_{6}\right] 0.2 \mathrm{~mol} / \mathrm{dm}^{3} 30 \mathrm{~min}+\mathrm{FeSO}_{4} 0.012 \mathrm{~mol} / \mathrm{dm}^{3} 30 \mathrm{~min}$ & 1.0 \\
\hline GAC-PBNP1 & $\begin{array}{c}\mathrm{FeCl}_{3} 0.1 \mathrm{~mol} / \mathrm{dm}^{3}+\mathrm{K}_{3}\left[\mathrm{Fe}(\mathrm{CN})_{6}\right] 0.2 \mathrm{~mol} / \mathrm{dm}^{3}+\text { slow addition of } \mathrm{H}_{2} \mathrm{O}_{2} 0.01 \mathrm{~mol} / \mathrm{dm}^{3} \text { induce formation of PBNP } \\
+ \text { subsequent adsorption onto GAC }\end{array}$ & 0.2 \\
\hline GAC-PBNP2 & $\begin{array}{c}\mathrm{FeCl}_{3} 0.1 \mathrm{~mol} / \mathrm{dm}^{3}+\mathrm{K}_{3}\left[\mathrm{Fe}(\mathrm{CN})_{6}\right] 0.2 \mathrm{~mol} / \mathrm{dm}^{3}+\text { sharp addition of } \mathrm{H}_{2} \mathrm{O}_{2} 0.01 \mathrm{~mol} / \mathrm{dm}^{3} \text { induce formation of PBNP } \\
+ \text { subsequent adsorption onto GAC }\end{array}$ & 0.9 \\
\hline GAC-PBNP3 & $\mathrm{FeCl}_{3} 0.02 \mathrm{~mol} / \mathrm{dm}^{3}+\mathrm{K}_{3}\left[\mathrm{Fe}(\mathrm{CN})_{6}\right] 0.001 \mathrm{~mol} / \mathrm{dm}^{3}+\mathrm{GAC}$ to induce formation + adsorption of PBNP & 1.5 \\
\hline GAC-PBNP4 & $\begin{array}{c}\text { GAC impregnation with } \mathrm{K}_{3}\left[\mathrm{Fe}(\mathrm{CN})_{6}\right] 0.001 \mathrm{~mol} / \mathrm{dm}^{3} \text { for } 30 \mathrm{~min} \text { with sonication }+\mathrm{FeCl}_{3} 0.02 \mathrm{~mol} / \mathrm{dm}^{3} \text { to induce formation }+ \\
\text { adsorption of PBNP }\end{array}$ & 1.4 \\
\hline
\end{tabular}

The UV-visible spectra of samples were recorded from 190-900 nm using a Shimadzu UV-1800 spectrophotometer. The maximum absorbance wavelength $\left(\lambda_{\max }\right)$ of OG is in the visible range, at $492 \mathrm{~nm}$. To assess mineralization, Total Organic Carbon was measured using a Shimadzu Toc-V CPN Total Organic Carbon analyzer. Hydrogen Peroxide concentration was determined by a Glycemia enzymatic test (Wiener Lab.). Total lixiviated iron was measured with the HACH FerroVer method.

\section{RESULTS AND DISCUSSION}

\section{A. Catalysts Characterization}

The catalysts with higher Fe content were selected for further analysis: GAC-PB3, GAC-PBNP2, GAC-PBNP3 and GAC-PBNP4.

Table II shows the BET surface area measured for support and the catalysts before and after treatment. A slight decrease (around 10\%) of the catalysts BET surface area with respect to GAC area is observed. This can be attributed to the active phase partially blocking the GAC porosity [10], [11].

\begin{tabular}{ccc}
\multicolumn{2}{c}{ TABLE II: BET SURFACE AREA $\left(\mathrm{M}^{2} / \mathrm{G}\right)$ OF THE CATALYSTS } \\
\hline \hline GAC & Fresh $(0 \mathrm{~min})$ & After reaction $(300 \mathrm{~min})$ \\
GAC-PB3 & 796 & 717 \\
GAC-PBNP2 & 724 & 684 \\
GAC-PBNP3 & 736 & 712 \\
GAC-PBNP4 & 704 & 676 \\
\end{tabular}

Fig. 1 illustrates SEM photographs of the support and catalysts surface, with 50000x magnification. The commercial GAC, being produced by chemical activation, presents a very irregular surface (Fig. 1a) generating pores of different sizes, which allow entrance of the PBNP. Catalysts also evidence rugged surfaces, in line with the high specific area measured both for them and the support. The catalyst prepared by impregnation (Fig. 1b) and subsequent formation of the PB directly on the surface show less discrete clusters of particles; the superficial iron content, determined by EDS is around $20 \%$ in weight, significantly larger than the total iron content, indicating concentration of active sites close to the outer part of the granular particles of around 2 mm mean diameter. Figs. 1d to $1 \mathrm{f}$ reveal that catalysts prepared by adsorbing PBNP have numerous discrete agglomerated nanoparticles on their surfaces.
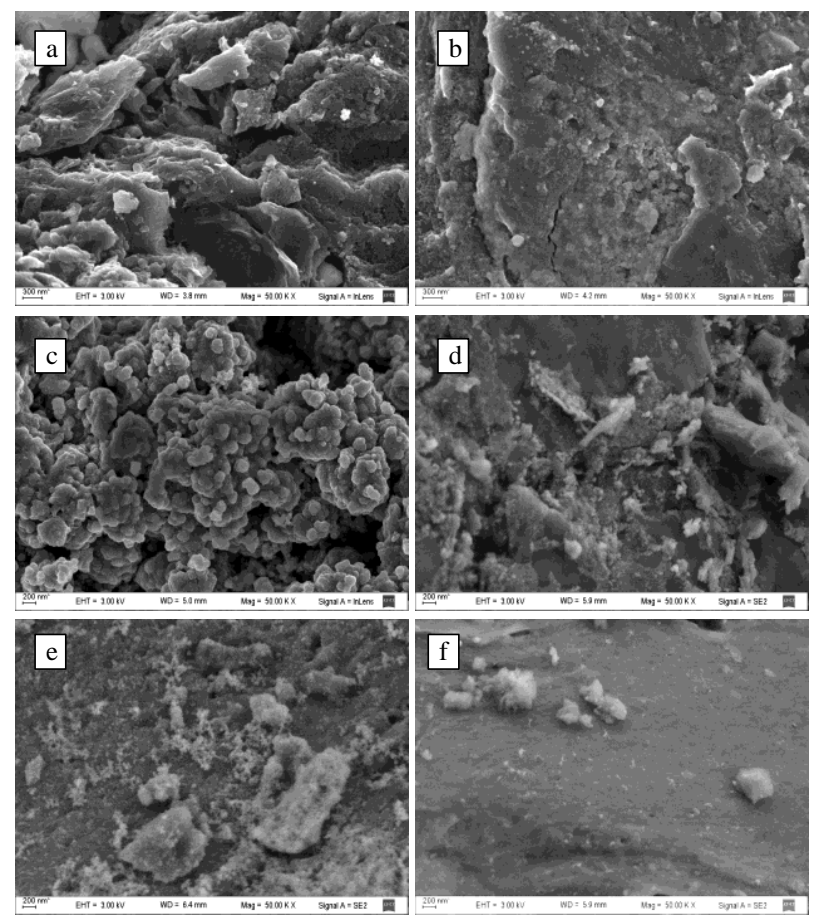

Fig. 1. SEM photographs of the support and catalysts (50000x) (a) GAC, (b) GAC-PB3, (c) GAC-PBNP2, (d) GAC-PBNP3 external view, (e) GAC-PBNP3 internal view, (f) GAC-PBNP4 
The catalyst obtained by adsorbing PBNP prepared ex-situ by a standard synthesis method has a very distinctive texture (Fig. 1c), arising apparently from a progressive deposition of PBNP, accumulating primarily on the outer surface of the catalyst grains; the iron content determined by EDS on the external shell is more than $60 \%$ in weight indicating an egg-shell type catalysts. A map of the Fe atoms points to a fairly homogeneous and very concentrated distribution of active sites. Catalysts obtained by inducing precipitation of the PBNP in-situ directly with the GAC display a rougher surface of smaller particles. For the GAC-PBNP3 and GAC-PBNP4, the iron content in the grains outer shell is similar to the total iron content and thus, active sites are distributed more homogeneously inside the catalyst grains. Actually, this is highlighted in Fig. 1e, which shows the internal part of a broken grain of GAC-PBNP3. Iron contents in the outer shell and in the internal part of the grain, determined by EDS, are similar and coincident with the total iron content. A map of iron atoms indicates again a fairly homogeneous and diluted distribution of active sites. Finally, the surface of the GAC-PBNP4 (Fig. 1f) displays a less rugged surface probably because it was subjected to sonication.

\section{B. Adsorption Experiments}

Runs with GAC and the catalysts were performed in the absence of $\mathrm{H}_{2} \mathrm{O}_{2}$. Equilibrium was not attained within 5 hours of operation. In all cases, the model solution was discolored in around $94 \%$ after 5 hours. It is worth to remark that the degree of discoloration is greater than the TOC consumption, indicating that GAC support and catalysts exhibit catalytic activity even without hydrogen peroxide addition. TOC reduction attained at $300 \mathrm{~min}$ is $72,72,60,66$ and $48 \%$ for GAC support, GAC-PB3, GAC-PBNP2, GAC-PBNP3 and GAC-PBNP4, respectively. This variation may be related to differences in BET surface area among the catalysts and to different inherent oxidant capacity.

Temporal evolution of UV-visible absorption spectra is shown in Fig. 2 for GAC support and GAC-PB3. The decrease of the peak at $492 \mathrm{~nm}$ observed in the UV-visible absorption spectra is related to the breakdown of the chromophoric group. The peaks at $331 \mathrm{~nm}$, characteristic of naphthalene rings, and at $248 \mathrm{~nm}$, characteristic of the benzene ring structures, also decrease with time. No peaks are present when total discoloration is accomplished and no colored intermediate species were generated in solutions.

The UV-visible spectrum of the sample taken at $180 \mathrm{~min}$ in the adsorption test with GAC support (remanent $\mathrm{TOC}=1.25$ $\mathrm{mol} / \mathrm{m}^{3}$ ) is compared with the one measured in a fresh OG solution with initial TOC of $1.25 \mathrm{~mol} / \mathrm{m}^{3}$ in Fig. 3. This comparison highlights the existence of intermediates than can not be detected in the UV-vis spectra arising from the support inherent oxidant capacity.

\section{Oxidation Experiments}

GAC can act itself as an electron-transfer catalyst promoting hydrogen peroxide decomposition. $65 \%$ of the initial $\mathrm{H}_{2} \mathrm{O}_{2}$ concentration is decomposed in 5 hours in the presence of GAC, whereas $97 \%$ with the prepared catalysts. The presence of Prussian Blue clearly enhances the oxidant decomposition, demonstrating its catalytic activity. The consumption rate of $\mathrm{H}_{2} \mathrm{O}_{2}$ slightly decreases in the presence of Orange $\mathrm{G}$, probably due to a partial blockage of active sites by the adsorbed dye, and by the competition of the organic species for the generated radicals' propagation. This is in line with outcomes reported with GAC for 4-chlorophenol and phenol by [2] and [12], respectively.

Discoloration profiles attained with the GAC and catalysts at $323 \mathrm{~K}$ are compared in Fig. 4. Total discoloration is achieved beyond 5 hours using the GAC, whereas it is completed at 3 hours of reaction time with all catalysts. The best catalyst in terms of discoloration rate is the one in which PBNP is prepared in situ inducing nanoparticles precipitation directly via the reducing character of the GAC itself (GAC-PBNP3).
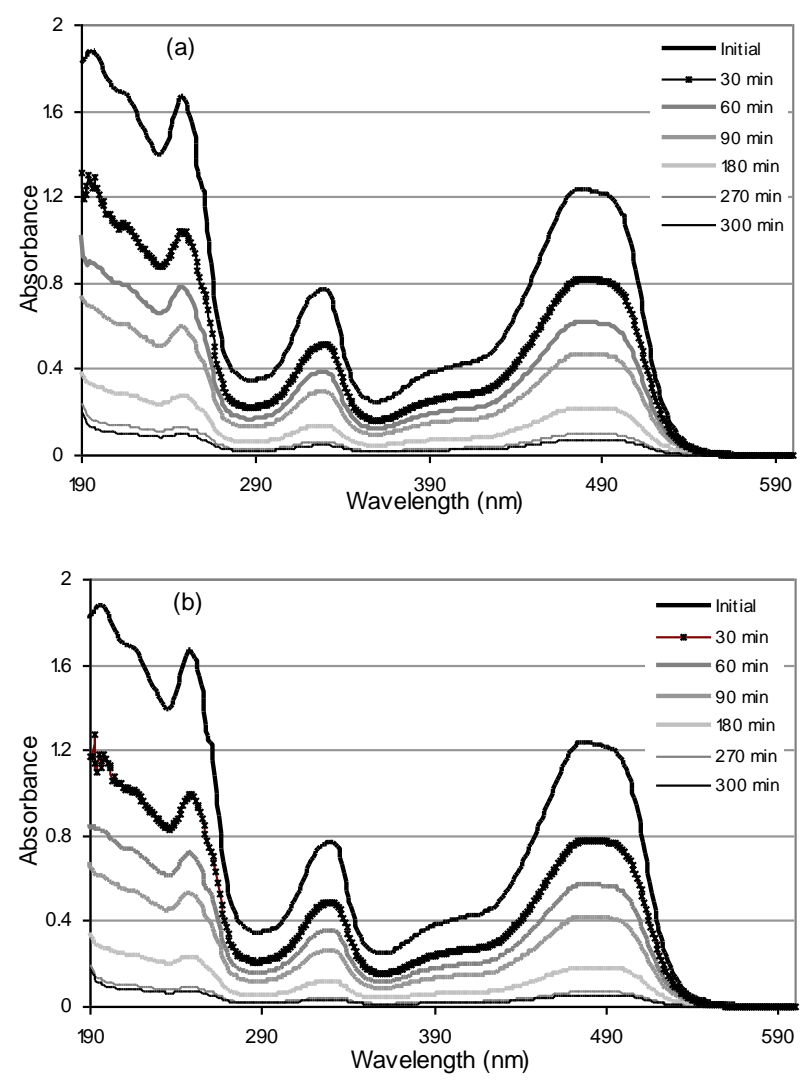

Fig. 2. UV-VIS spectral changes along time in runs performed without $\mathrm{H}_{2} \mathrm{O}_{2}$ using (a) GAC support; (b) GAC-PB 3.

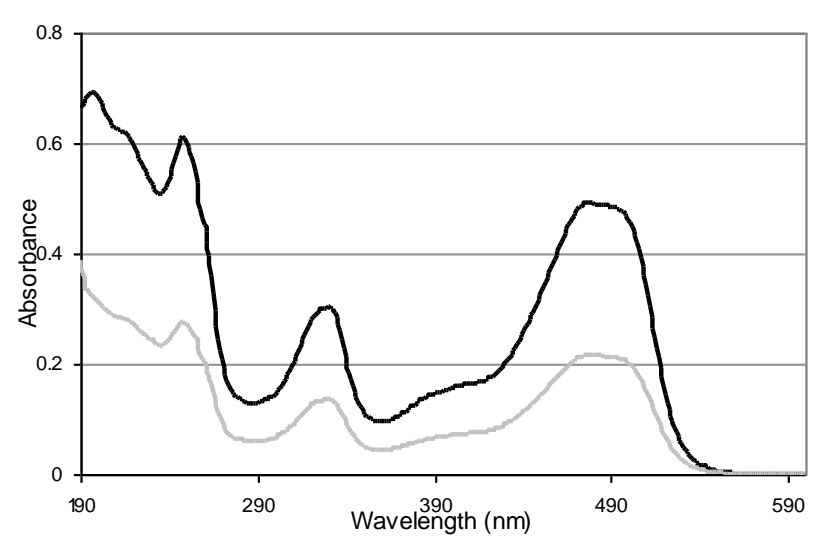

Fig. 3. UV-visible spectra (TOC $=1.25 \mathrm{~mol} / \mathrm{m}^{3}$ ). ( $(-$ ) sample taken at 180 min in the adsorption test with GAC support; (_) fresh OG solution. 


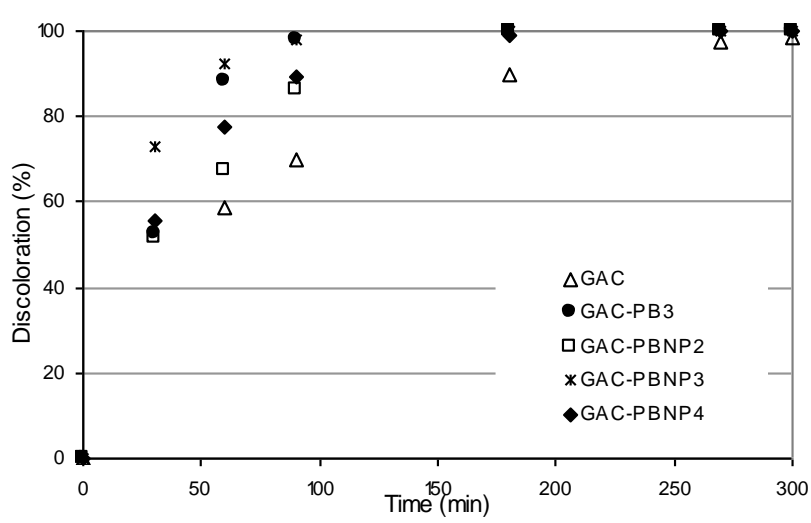

Fig. 4. Discoloration profiles for GAC support and catalysts.

Fig. 5 shows TOC conversion profiles. Contrary to expectations, TOC consumption in oxidative conditions is lower than the reduction attained with the GAC. Reactions of oxidative chemicals with organic compounds in aqueous solution can alter the GAC adsorption performance [13]. Fenton oxidation leads to the formation of intermediate products, which may additionally block the pores entrance while diffusing outwards of the adsorbent particles and, being of lower molecular weight, they are likely less adsorbable than OG. Moreover, as mineralization proceeds, intermediates may be more polar, like carboxylic acids, and thus, even less adsorbable molecules. Hence, intermediate products desorbing from the solid catalysts towards the surrounding media contribute to increase the TOC concentration in solution compared to the situation when only GAC is used.

Fig. 6a presents the temporal evolution of UV-visible absorption spectra in runs performed with $\mathrm{GAC}$ and $\mathrm{H}_{2} \mathrm{O}_{2}$. The presence of hydrogen peroxide is reflected in the spectra through a higher absorbance measured between 190 and 240 $\mathrm{nm}$. When catalysts are employed (Fig. 6b), the occurrence of further oxidation reactions is evidenced by the presence of a residual peak at $205 \mathrm{~nm}$. The change in the shape of the spectrum along the reaction time is indicative of dye oxidation. Reference [14] also addressed this trend in the photocatalytic oxidation of Orange G. These authors stated that the peak at $205 \mathrm{~nm}$ is indicative of the presence of end products (nitrates) and the formation of $\mathrm{N}$-containing organics.

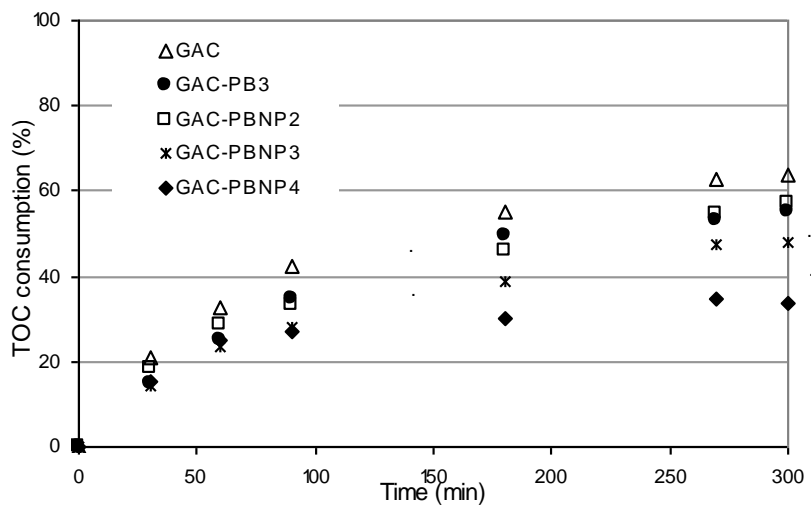

Fig. 5. TOC consumption profiles for GAC support and catalysts.

\section{Stability Experiments}

Catalyst deactivation in heterogeneous catalytic Fenton process can be attributed to attrition by reduction of the catalyst specific surface area, poisoning of the catalytic agents by compounds formed during oxidation, surface deposition and strong adsorption on the carbon, and most commonly the leaching by dissolution of the active metal sites from the catalysts into the acidic reaction medium under Fenton system [15].
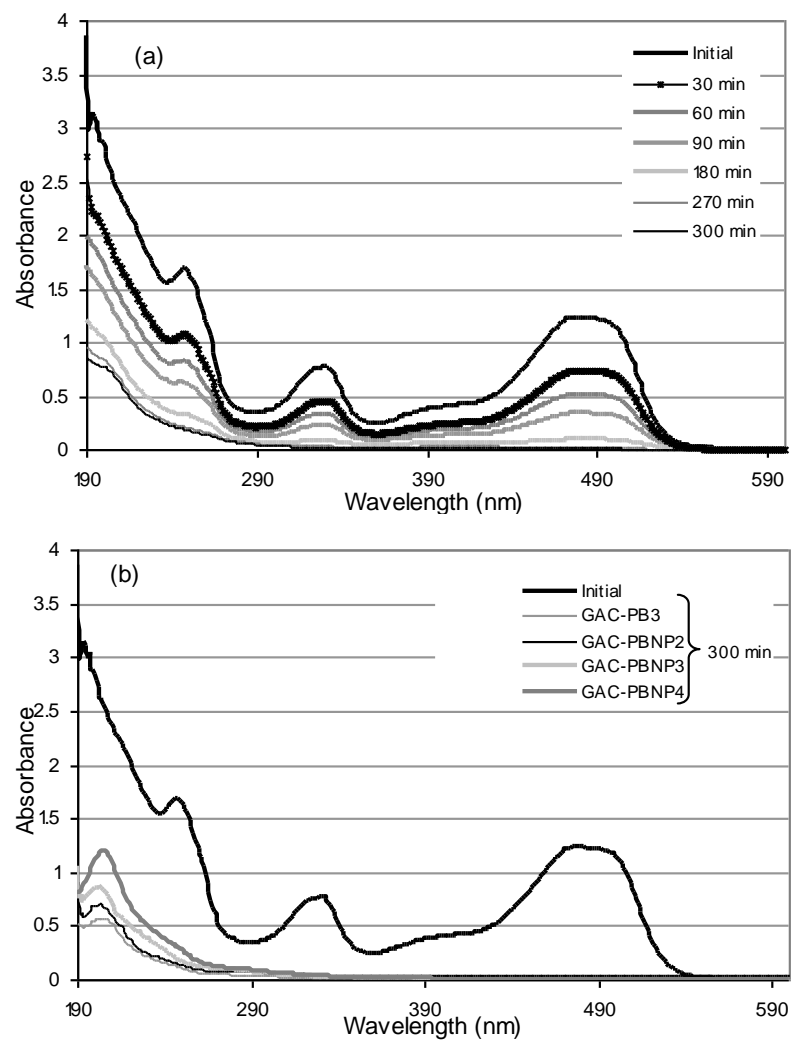

Fig. 6. UV-VIS spectral changes along time in runs performed with $\mathrm{H}_{2} \mathrm{O}_{2}$ using (a) GAC support; (b) catalysts.
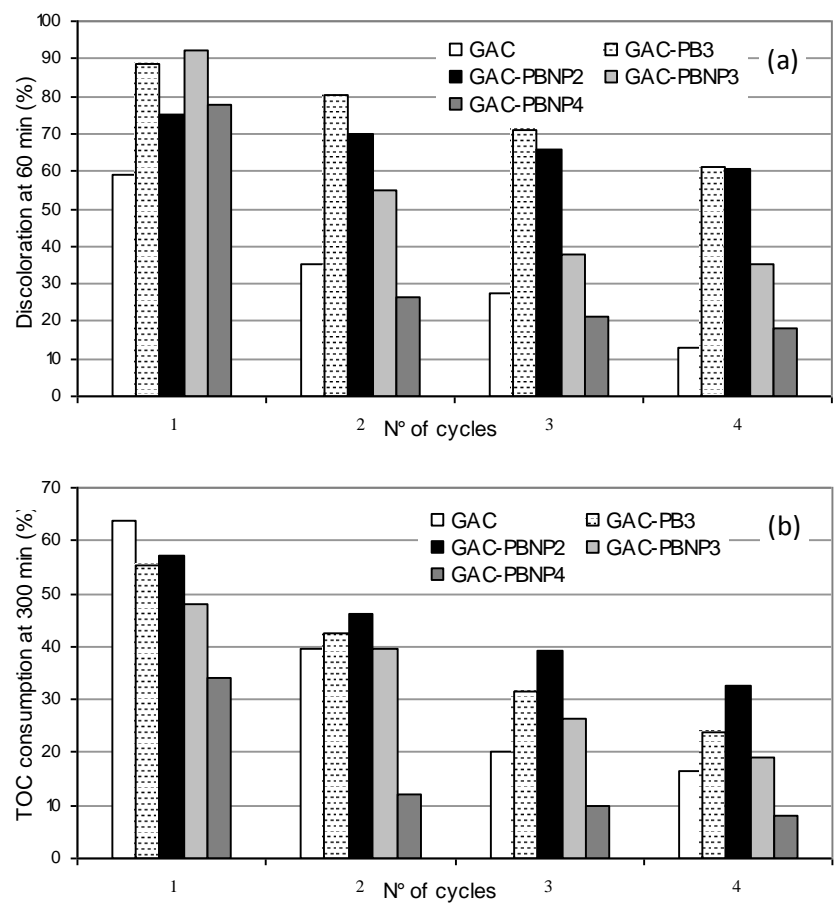

Fig. 7. Outcomes obtained after reusing the GAC and the catalysts. (a) Discoloration attained at 60 minutes; (b) TOC consumption after $300 \mathrm{~min}$.

Further experiments were performed to examine catalysts 
stability. The solid was recovered from the solution after the reaction, dried at room temperature and tested again with fresh OG solution at the same reaction conditions. Figs. 7a-b sum up outcomes obtained after reusing the GAC and the catalysts.

Complete discoloration is achieved after 4 reaction cycles of 5 hours each with the catalysts, whereas only $80 \%$ is discolored with the GAC after the second cycle. This indicates that the GAC becomes saturated relatively faster than the catalysts. Fig. 7a shows that the GAC-PBNP2 is the most stable catalyst regarding the discoloration rate, even if GAC-PB3 shows better performance in the first cycles.

On the other hand, a decrease in TOC consumption is observed in all cases, likely arising from a gradual loss in the adsorption capacity apart from the loss in the catalytic activity. The GAC-PBNP2 is again the more stable catalyst for TOC conversion and also exhibits the highest efficiency in this case. The GAC-PB3 and GAC-PBNP3 perform worse and deactivate faster. The GAC-PBNP4 exhibits, in general terms, the worst behavior in terms of stability.

A possible explanation of the activity decrease when the catalysts are is reused could be attributed to the iron lost.

TABLE III: IRON LEACHING

\begin{tabular}{|c|c|c|c|c|}
\hline & Initial iron & Total Fe in solution & Iron lea & hing $(\%)$ \\
\hline & content $(\%)$ & after $5 \mathrm{~h} .\left(\mathrm{mg} / \mathrm{dm}^{3}\right)$ & after $5 \mathrm{~h}$ & after $20 \mathrm{~h}$ \\
\hline GAC-PB3 & 1.0 & 1.22 & 4.7 & 23 \\
\hline GAC-PBNP2 & 0.9 & 0.80 & 3.4 & 11 \\
\hline GAC-PBNP3 & 1.5 & 0.95 & 2.4 & 6 \\
\hline GAC-PBNP4 & 1.4 & 0.90 & 2.5 & 5 \\
\hline
\end{tabular}

Table III reports low values of iron leaching after 5hours; less than $5 \%$ wt of the original content with all tested catalysts. Generally, higher Fe leaching has been reported by other authors for catalysts prepared on GAC supports [4], [16].

Iron leaching for reused catalysts is also included in Table III. A significant difference among the catalysts is the relatively low iron leaching exhibited by the catalysts prepared with PBNP after four cycles. The Fe lixiviated decreases along the cycles. The decrease of the iron leaching degree and the catalytic activity could be attributed to the formation of carbonaceous deposits over the catalyst surface as well as the dominant presence of refractory compounds under mild oxidizing conditions [17].

\section{CONCLUSIONS}

The prepared catalysts have shown to be able to completely decolorize and partially oxidize the Orange $G$ present in the model wastewater within 3 hours in the studied operating conditions. GAC-PBNP2 exhibited the best performance in terms of TOC conversion and stability. For this catalyst, PBNP were prepared via the reaction between $\mathrm{FeCl}_{3}$ and $\mathrm{K}_{3} \mathrm{Fe}(\mathrm{CN})_{6}$ adding the reducing agent $\left(\mathrm{H}_{2} \mathrm{O}_{2}\right)$ suddenly (ex-situ) and adsorbed onto the GAC . Given that complete mineralization is not achieved, further work is needed to determine whether this treatment leads to non-toxic organic intermediates. Ongoing investigation focuses on the assessment of the toxicity of the treated OG model wastewater.

\section{ACKNOWLEDGMENT}

We want to express our gratitude to $\mathrm{C}$. Rodriguez and $\mathrm{H}$. Asencio for their technical support.

\section{REFERENCES}

[1] E. Neyens and J. Baeyens, “A Review of Classic Fenton's Peroxidation as an Advanced Oxidation Technique," J. Hazard. Mater., vol. 98, pp 33-50, March 2003.

[2] H. H. Huang, M. C. Lu, J. N. Chen, and C. T. Lee, "Catalytic decomposition of hydrogen peroxide and 4-chlorophenol in the presence of modified activated carbons," Chemosphere, vol. 51, pp. 935-943, Jan. 2003.

[3] H. T. Gomes, S. M. Miranda, M. J. Sampaio, A. M. T. Silva, and J. L. Faria, "Activated carbons treated with sulphuric acid: Catalysts for catalytic wet peroxide oxidation," Catal. Today, vol. 151, pp. 153-158, Feb. 2010.

[4] J. H. Ramirez, F. J. M. Hodar, A. F. P. Cadenas, C. M. Castilla, C. A. Costa, and L. M. Madeira, "Azo-dye Orange II degradation by heterogeneous Fenton-like reaction using carbon-Fe catalysts," Appl. Catal. B-Environ., vol. 75, pp. 312-323, Sept. 2007.

[5] F. Duarte, F. J. M. Hodar, and L. M. Madeira, "Influence of the Particle Size of Activated Carbons on Their Performance as Fe Supports for Developing Fenton-like Catalysts," Ind. Eng. Chem. Res., vol. 51, pp. 9218-9226, June 2012.

[6] D. Moscone, D. D. Ottavi, D. Compagnone, and G. Palleschi, "Construction and Analytical Characterization of Prussian Blue-Based Carbon Paste Electrodes and Their Assembly as Oxidase Enzyme Sensors," Anal. Chem., vol. 73, pp. 2529-2535, April 2001.

[7] S. Q. Liu, S. Cheng, L. R. Feng, X. M. Wang, and Z. G. Chen, "Effect of alkali cations on heterogeneous photo-Fenton process mediated by Prussian blue colloids," J. Hazard. Mater., vol. 182, pp. 665-671, Oct. 2010.

[8] H. Wang and Y. Huang, "Prussian-blue-modified iron oxide magnetic nanoparticles as effective peroxidase-like catalysts to degrade methylene blue with $\mathrm{H}_{2} \mathrm{O}_{2}$," J. Hazard. Mater., vol. 191, pp. 163-169, April 2011.

[9] R. Y. Z. Song, B. Y. Y. Chai, and J. W. P. Fu, "Multilayer structured amperometric immunosensor based on gold nanoparticles and Prussian blue nanoparticles/nanocomposite functionalized interface,' Electrochimica Acta, vol. 55, pp. 1778-1784, Feb. 2010

[10] A. Rey, M. Faraldos, J. A. Casas, J. A. Zazo, A. Bahamondea, and J. J. Rodríguez, "Catalytic wet peroxide oxidation of phenol over Fe/AC catalysts: Influence of iron precursor and activated carbon surface," Appl. Catal. B-Environ., vol. 86, pp. 69-77, Feb. 2009.

[11] F. Duarte, F. J. Maldonado-Hódar, and L. M. Madeira, "New insight about orange II elimination by characterization of spent activated carbon/Fe Fenton-like catalysts," Appl. Catal. B-Environ., vol. 129, pp. 264-272, Jan. 2013.

[12] A. Bach and R. Semiat, "The role of activated carbon as a catalyst in GAC/iron oxide/H2O2 oxidation process," Desalination, vol. 273, pp. 57-63, April 2010

[13] V. Snoeyink and S. Summers, "Adsorption Science and Technology," in Proc. of the Second Pacific Basin Conf. on Adsorption Science and Technology, Brisbane, Australia, 2000, chapter 13.

[14] F. Harrelkas, A. Paulo, M. M. Alves, L. E. Khadir, O. Zahraa, M. N Pons, and F. P. van der Zee, "Photocatalytic and combined anaerobicphotocatalytic treatment of textile dyes," Chemosphere, vol. 72, pp. 1816-1822, May 2008

[15] A. N. Soon and B. H. Hameed, "Heterogeneous catalytic treatment of synthetic dyes in aqueous media using Fenton and photo-assisted Fenton process," Desalination, vol. 269, pp. 1-16, Nov. 2011.

[16] A. Rodriguez, G. Ovejero, J. L. Sotelo, M. Mestanza, and J. Garcia, "Heterogeneous Fenton Catalyst Supports Screening for Mono Azo Dye Degradation in Contaminated Wastewaters," Ind. Eng. Chem. Res., vol. 49, pp. 498-505, Oct. 2010.

[17] J. A. Melero, G. Calleja, F. Mart'inez, R. Molina, and M. I. Pariente, "Nanocomposite $\mathrm{Fe}_{2} \mathrm{O}_{3} / \mathrm{SBA}-15$ : An efficient and stable catalyst for the catalytic wet peroxidation of phenolic aqueous solutions," Chem. Eng J., vol. 131, pp. 245-256, July 2007. 


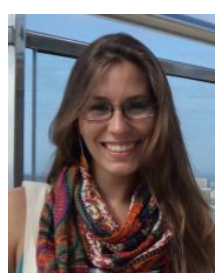

Lucila I. Doumic was born in Mar del Plata, Argentina on October 5th 1985. She received her Chemical Engineering degree at the National University of Mar del Plata (Argentina) on December 2009. She is currently a doctoral fellow of the National Council of Science and Technology (CONICET) and permanent teaching assistant of Chemical engineering at the National University of Mar del Plata (Argentina). He research interests are focused on chemical reaction engineering, in particular, advance oxidation processes in multiphase reactors.

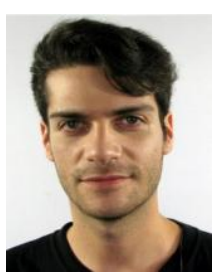

Gabriel L. Salierno was born in Buenos Aires, Argentina on December 19th 1983. He had received his Chemistry degree at the University of Buenos Aires (Argentina) on March 2011. He's currently a doctora fellow of the National Council of Science and Technology (CONICET) and teaching assistant at University of Buenos Aires. His main interests are focused on fluid dynamics of multiphase reactors for and renewable energy. the development of cleaner processes, biotechnology

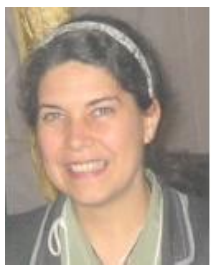

Miryan C. Cassanello was born in Asunción Paraguay on April 18th 1962. She received her Chemistry degree at the University of Buenos Aires (Argentina) in 1987 and her $\mathrm{PhD}$ degree of the University of Buenos Aires in 1992. She has over 20 years of working experience in academia. She is Independent Researcher at National Council of Science and Technology (CONICET) and Professor of
Industrial Chemistry at the University of Buenos Aires (Argentina). Her research interests are focused mainly on multiphase reactors and process monitoring.

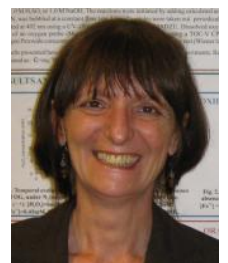

Patricia M. Haure was born in Mar del Plata, Argentina, on September 15, 1957. She received her Chemical Engineering degree at the National University of Mar del Plata (Argentina) and her PhD degree at the University of Waterloo, Waterloo, Ontario (Canada). She has over 24 years of working experience in academia. She is Independent Researcher at National Council of Science and Technology (CONICET) and professor of Chemical engineering at the National University of Mar del Plata (Argentina). Her research interests are focused on chemical reaction engineering, in particular, advanced oxidation processes in multiphase reactors and biological treatments.

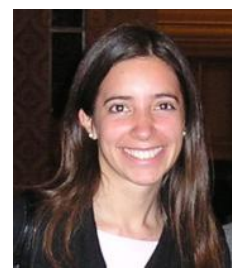

María A. Ayude was born in Mar del Plata, Argentina, on June 26, 1977. She received her Chemical Engineering degree and her MChE at the National University of Mar del Plata (Argentina) and her $\mathrm{PhD}$ degree at the University of Buenos Aires (Argentina). She has 15 years of academic experience. She is Adjunct Researcher at National Council of Science and Technology (CONICET) and auxiliary professor of Chemical engineering at the National University of Mar del Plata (Argentina). Her research interests are focused on chemical reaction engineering, in particular, advanced oxidation processes in multiphase reactors: experimental and modeling. 